\title{
COMPROMISO FILOSÓFICO EN TIEMPOS DE PESADUMBRE
}

Myriam Hernández Domínguez y Miguel Mandujano Estrada (coords.), Ética y política. Ensayos indisciplinados para repensar la filosofía, Granada: Editorial Comares, 2021, 174 pp.

Este libro, que reúne doce ensayos «indisciplinados» de autores de distintas generaciones y áreas filosóficas, se presenta como la continuación natural del anterior Repensar la Filosofía. Ensayos desde la perplejidad. Homenaje a Javier Muguerza, publicación colectiva que reunió prácticamente al mismo equipo de colaboradores (repiten once de los catorce que participaron en aquel tomo), procedentes del Departamento de Historia y Filosofía de la Ciencia, la Educación y el Lenguaje de la Universidad de La Laguna y de la Cátedra Cultural Javier Muguerza -codirigida por Pablo Ródenas Utray y Vicente Hernández Pedrero-, así como del grupo de investigación Repensar la Filosofía -coordinado, a su vez, por el citado Hernández Pedrero-. La reseńa que elaboramos de aquel libro se tituló «Racionalismo crítico para una época de incertidumbre», entendiendo como tal período el marco sociopolítico mundial establecido a partir de la infausta crisis económica de 2008; ahora, y tras el confinamiento planetario que se inició a raíz del covid-19, pocas dudas caben de que la «incertidumbre» que otrora padecíamos se ha metamorfoseado, con desagradable brusquedad, en una "pesadumbre» sostenida sobre la base de una precariedad aún más cruda que la de su denominación precedente. Por este motivo no es de extrañar que los coordinadores de Ética $y$ politica subrayen, en su escueta presentación, que, en efecto, "corren tiempos inciertos", si bien de inmediato añaden que «los tiempos inciertos son propicios [...] también para el asombro y para renovar la búsqueda de sentido", de ahí que concluyan diciendo que "corren tiempos filosóficos", lo que equivale a afirmar que la reflexión sosegada y comprometida con la tradición y el lenguaje siempre es pertinente por muy adversa y hostil que sea la coyuntura histórica, ya que dicha reflexión sirve no solo de acicate en medio de la grotesca charlatanería que contamina el ambiente, sino también para «revisar y cuestionar el conjunto de consideraciones ético-políti- cas que han conformado y conforman nuestro mundo" ${ }^{1}$. Pensar y repensar filosóficamente en estos duros momentos de indefinida pesadumbre; ése, y no otro, es el objetivo de este heterogéneo conjunto de ensayos.

Pablo Ródenas (reconocido discípulo de Muguerza) es el encargado de inaugurar la serie de trabajos que integran el libro, y lo hace desde su especialidad, la filosofía política ${ }^{2}, o$, para ser más exactos, desde la perspectiva poli(é) $\mathrm{tica}^{3}$. Ródenas, a lo largo de numerosos escritos, ha definido en profundidad este singular neologismo, mediante el cual pretende recuperar las «resonancias éticas» propias de la polis griega que la acción política «ha ido perdiendo en la modernidad" y que, asimismo, le permite el abandono de la razón meramente instrumental y el reconocimiento "de lo vario, lo diverso y lo plural» ${ }^{4}$

1 P. IX.

${ }^{2}$ Consideramos pertinente reproducir la breve definición que Mario Bunge (fallecido justo antes del confinamiento, es decir, durante la transición de la incertidumbre a la pesadumbre) establece de la disciplina y de la figura del filósofo político: «En tanto que los politólogos describen y explican la política -sostiene-, los filósofos la examinan de manera crítica y sugieren mejoramientos y, en ocasiones, rasgos sociales radicalmente diferentes. Los filósofos políticos proponen escenarios y sueños allí donde los científicos sociales ofrecen instantáneas de las organizaciones políticas existentes». Por esta razón, concluye el autor argentino, «la filosofía política no es un lujo sino una necesidad, ya que es vital para entender la actualidad política y, sobre todo, para pensar un futuro mejor», cf., M. Bunge, Filosofía Politica. Solidaridad, cooperación y Democracia Integral, Barcelona: Gedisa, 2009, pp. 9 y 17.

3 ¿Por qué esa necesaria introducción de la "ética» dentro de la "política»?; de nuevo recurrimos a la autorizada voz de Bunge para explicarlo aforísticamente: «La filosofía posee una arista moral que la ciencia política no tiene»; "Sostengo que el componente más importante de la acción política es el moral, aunque también sea el menos visible»; «La política responsable no se basa en la ideología sino en la filosofía, especialmente en la ética, así como en la tecnología social", cf. M. Bunge, ibidem, pp. 10, 26 y 27.

4 Pablo Ródenas Utray, "Un diálogo entre perplejos. A la busca del individuo poli(é)tico y comunipolita», incluido en el volumen Disenso e incertidum-

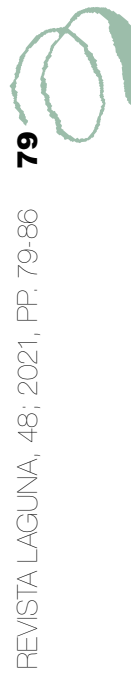


mediante la aplicación estratégica de una racionalidad crítica y autocrítica, práctica y empática, voluntarista y cooperativa.

Aunque en opinión de Mario Bunge uno de los déficits que arrastra la filosofía política es su excesivo interés por analizar las obras de autores del pasado que poco aportan a los problemas del presente (en la medida en que cada pensador es preso de su época histórica y sus formas de producción y prejuicios socioculturales ${ }^{5}$ ), Ródenas se pregunta si uno de los problemas de los actuales regímenes democráticos pasa por un exceso de voluntad de poder que, entre otros nocivos efectos, mantiene anestesiada a la ciudadanía en el "conformismo» y la «insensatez»" ${ }^{6}$. Para dar una respuesta pormenorizada a ese pertinente interrogante desde el razonamiento crítico poli(é) tico (y que, en última instancia, lo que persigue es «el empoderamiento [...] que necesita la democracia equitativista ${ }^{7}$ ), Ródenas se apoya en la interpretación del autor de Así habló Zaratustra que realiza Martin Heidegger, pues a su juicio el filósofo del Dasein "presenta suficientes credenciales de sapiencia para abordar la cuestión de la voluntad de poder en Nietzsche como deriva de la muerte de Dios, el "todopoderoso" ${ }^{8}$. Ródenas se muestra en todo momento enormemente crítico con Heidegger, pero, eso sí, desde una posición de sumo respeto; de ahí que, aun-

bre. Un homenaje a Javier Muguerza, Madrid, Plaza y Valdés, 2006, de J. Francisco Álvarez y R.R. Aramayo (eds.), p. 172.

5 Sirvan estas dos sentencias aforísticas para entender el punto de vista radical de Bunge: «La filosofía política no es todavía un área bien definida: planea entre la teoría política y el fantaseo utópico. Dedica demasiado tiempo a analizar las obras de Platón, Aristóteles, Tomás de Aquino, Hobbes, Spinoza, Locke, Montesquieu, Kant, Rousseau o Bentham. Pero ninguno de estos pensadores pudo haber anticipado ninguno de los problemas políticos más apremiantes de nuestra época»; "Leer libros antiguos es un agradable pasatiempo, pero no reemplaza la investigación de las cuestiones candentes y de los problemas filosóficos que estas suscitan", cf., M. Bunge, cit., pp. 10 y 23.

${ }^{6}$ P. 17.

7 P. 1. Para un estudio más extenso del término «equitativista" se recomienda la consulta del artículo de Ródenas «El filosofar iuspoli(é)tico equitativista (una tentativa de Filosofía Política de la moral y el derecho)", en Laguna: Revista de Filosofía, n. ${ }^{\circ} 30$. 8 P. 3. que discrepe a fondo con el autor de Caminos de bosque (entre otras cuestiones por la deformación que hace de Nietzsche para favorecer sus propios intereses filosóficos), a su vez reconoce su indiscutible calidad intelectual.

Por lo tanto, tenemos sobre el tablero de juego al religioso, antiético y premoderno Heidegger analizando al ateo, antiético y moderno Nietzsche. (No es casualidad, según parece, que en lo que coincidan ambos autores sea en el desdén que muestran hacia esa ética que Ródenas se empeña en reivindicar como elemento básico para los regímenes democráticos ${ }^{9}$ ). A juicio de Ródenas, los cimientos de la modernidad que tanto le duele a Heidegger se encuentran representados por el igualitarismo político universal (Spinoza), la ética universal (Kant), la sociedad de clases (Marx) y, finalmente, por la crítica de los valores sacros/absolutos y su reemplazo por unos valores construidos/flexibles (Nietzsche) ${ }^{10}$.

9 Mario Bunge ya advirtió que "con la excepción de Nietzsche, quien despreciaba la ética, y de Heidegger, quien decretó que era imposible, todo el mundo admite la necesidad de la ética", cf., Filosofía Política, cit., p. 185.

${ }^{10}$ Las aportaciones intelectuales inequívocamente modernas de Spinoza, Kant, Marx y Nietzsche coinciden con la evolución de la democracia liberal y su transformación en la política, la economía, la cultura y la sociedad. Tal y como expone con acierto Roberto Rodríguez Guerra en su artículo del libro (pp. 111126), existen cuatro etapas históricas fundamentales del liberalismo clásico, a saber: 1) el gobierno representativo en oposición a la democracia (entre mediados del XVII y principios del XVIII, período en el que tenemos a Locke y a Spinoza, pero también a Cervantes, el símbolo poético de la modernidad, en palabras de Pedro Cerezo, tal y como recoge en el libro Francisco Javier Clemente Martín); 2) de la democracia "antigua» a la democracia «moderna» (entre mediados del Xviı y principios del xix, período del que forma parte Kant y la Ilustración); 3) de la nueva democracia a la democracia representativa (en la primera mitad del xIx, donde se situarían Tocqueville, Stuart Mill y Marx); 4) la aceptación del término "democracia" por parte del liberalismo (segunda mitad del xIx, concluyendo, por tanto, con la figura del nihilista Nietzsche). Aunque tampoco conviene olvidar, como matiza Daniel Bernabé, que la espiral de transformaciones que trajeron consigo los tres siglos de desarrollo modernista en los que el liberalismo acabó imponiéndose al absolutismo no supuso una ruptura con la dialéctica hegeliana del amo y el esclavo, ya que «todos han pasado de súbdi- 
Respecto a Heidegger, la cuestión no tiene mayor recorrido: lo que a él le preocupa es la ausencia de Dios que arranca con Nietzsche (recordemos, como admitió el propio Heidegger en su célebre entrevista póstuma a Der Spiegel, que «sólo un Dios puede aún salvarnos»), por esa razón, para Ródenas, el rescate heideggeriano de «valores supremos» se instala «en la más alta cumbre de la metafísica, esa que creía haber superado» ${ }^{11}$.

Ródenas remata su ensayo dejando constancia de las incontables manifestaciones reaccionarias que se están apoderando del espacio público en las democracias actuales, lo que desde su punto de vista supone una grave insuficiencia de la razonabilidad poli(é)tica y la equidad ${ }^{12}$. Y deja en el aire la incómoda pregunta de cómo es posible que la ciudadanía no reaccione a este y otros peligros que asechan a la frágil convivencia planetaria y se quede "como anestesiada por los disvalores del conformismo y la insensatez»» ${ }^{13}$. Una pregunta que, como veremos, será respondida más adelante.

Después de Nietzsche -el autor que cierra el siglo xIx y abre el xx- la democracia liberal se consolida, y ello permitió, entre otras cosas, la aparición de los movimientos vanguardistas que cuestionaron la autoridad y los dogmas absolutos -incluido el tiempo, que ha dejado de

tos a ciudadanos, pero algunos, la mayoría de hecho, portan ahora unas nuevas cadenas», $c f$., D. BERNABÉ, La trampa de la diversidad. Cómo el neoliberalismo fragmentó la identidad de la clase trabajadora, Madrid: Akal, 2018, p. 39.

${ }_{11}$ P. 6. Según Ródenas, «a lo que aspiraba el filósofo de Messkirch no era a desacralizar, sino a resacralizar el mundo" (p. 5). (Esa "fe cristiana a toda de prueba» de Heidegger explica, por ejemplo, que un número nada desdeñable de sus discípulos sean teólogos, católicos confesos y creyentes desorientados. El mismo Gianni Vattino, por ejemplo, en una entrevista reciente, reconoció -se agradece la sinceridad- que a Heidegger «la única manera de leerlo útilmente es como un pensador cristiano [...]. Yo lo veo como un intérprete de Occidente que se inspira en el cristianismo como hilo conductor", cf., El Pais, 28/06/2019, p. 33.) Por otra parte, y en relación con el apartado de los valores, para Ródenas cualquier valor «deber ser, además de construido y justificado, debatido, acordado e instaurado de forma democrática. Por tanto, nunca ninguno podrá ser sagrado», p. 15.

${ }_{12}$ P. 17.
13 Ibidem ser eterno para convertirse en efímero-, por ese motivo algunos autores consideran los años que van de 1900 a 1939 como el último escalón de la modernidad (no hay que olvidar, como muy bien apunta en su texto Rayco José Herrera Reyes, que nos encontramos en plena resaca de la «muerte de Dios», así como de los ideales humanistas vigentes hasta entonces ${ }^{14}$ ). El problema es que durante este trepidante espacio temporal también se suceden la Primera Guerra Mundial y la Revolución rusa; para Daniel Bernabé, a causa de la segunda, "la burguesía, temerosa de que el virus rojo se extienda, deja a un lado la coartada civilizatoria del liberalismo y lo despoja de sus ropajes de derechos y libertades»; por esta razón, prosigue, "financia al fascismo, lo arma, le da cobertura legal y legitimidad electoral $\aleph^{15}$.

Pero antes de que el fascismo engordara con premeditación y alevosía hasta desencadenar la Segunda Guerra Mundial -tras el ensayo previo de la Guerra Civil Española-, los valiosos miembros de la Escuela de Frankfurt ${ }^{16}$ ya se encontraban analizando con lupa cada mácula del complejo engranaje social de entonces, lo que los llevaría a concluir, como así demostrarían los trágicos acontecimientos futuros, que las formas de dominio autoritarias se estaban apoderando del planeta. En este contexto de «transformaciones del mundo liberal burgués» ${ }^{17}$ se encuadra la sugestiva "teoría de los rackets» que elaboraron Max Horkheimer y Theodor Adorno y que es comentada aquí por Marcos Hernández y Carlos Marzán: «a pesar», señalan los segundos, «de que

14 P. 99.

15 D. Bernabé, La trampa de la diversidad, cit., p. 41 .

16 El economista marxista Alfred Sohn-Rethel (1899-1990), a quien Chaxiraxi Escuela Cruz dedica en el libro un cuidadoso, sobrio y preciso texto en que reivindica su figura - un tanto olvidada, nos recuerda, en el ámbito bibliográfico español-, estuvo próximo al grupo de la Teoría Crítica, si bien nunca llegó a involucrarse a fondo con ellos. No obstante, la influencia frankfurtiana de A. Sohn-Rethel es innegable en citas como la que Chaxiraxi Escuela Cruz ha seleccionado para encabezar su trabajo: "Como marxista me había quedado clara una cosa. Mientras no se le diera una respuesta materialista a la pregunta por el sujeto trascendental, el materialismo permanecerá injustificado", p. 127.

17 P. 22. 
esa teoría sólo tiene un carácter fragmentario, no carece de relevancia para comprender el desarrollo de la Teoría Crítica y la evolución de las sociedades contemporáneas ${ }^{18}$. El vocablo «racket», surgido del mundo del hampa ${ }^{19} \mathrm{y}$ propio de las grandes ciudades (recordemos que en las primeras décadas del pasado siglo se produce un ensalzamiento de las metrópolis), es un concepto, según explican Hernández y Marzán, que designaba a los «grupos de individuos -que funcionaban tanto de modo legal como ilegalcuyo objetivo era alcanzar parcelas de poder y mantenerse en ellas, y que defendían sus posiciones ofreciendo protección a cambio de lealtad. Para salvaguardar sus intereses no sólo ejercían la violencia física o simbólica, sino el chantaje y la extorsión en diferentes grados» ${ }^{20}$. (A modo

18 P. 20.

19 La procedencia del vocablo explica el guiño divertido de Hernández y Marcos de encabezar cada nueva entrada de su artículo con citas de películas de gánsteres, particularmente de la obra mayor dentro del género: El padrino (1972), de Francis Ford Coppola. Siguiendo con esta línea de referencias culturales que parece emular el tono más lúdico de Dialéctica de la Ilustración, Hernández y Marcos dan cuenta, en una suculenta página, de su sensibilidad cinéfila al citar películas con la temática de los bajos fondos, desde The Racket (1928), de Lewis Milestone, a la reciente El irlandés (2019), de Martin Scorsese. Se echa en falta, eso sí, la mención a El precio del poder (1983), de Brian de Palma, que consideramos el título de este género que más influencia ha tenido entre el público en las últimas décadas, al tratarse de una versión oscura del populista American Dream.

${ }^{20}$ P. 21. Más adelante recalcan los autores que «la categoría del racket [...] pretendía describir un sistema de dominio directo sin una justificación ideológica significa» (p. 26). Retengamos esta palabra: dominio. Porque de lo que se trata, en última instancia, es de una cuestión de poder, y éste se manifiesta desde el momento en que un individuo sabe que puede imponerse a otro, lo que explica que "no sólo existían rackets entre los privilegiados, sino, incluso, entre los menos favorecidos» (p. 28). (La figura del racket se refleja perfectamente en las ambiciosas novelas gráficas de Will Eisner, sobre todo en Ansia de vivir, La avenida Dropsie y Las reglas del juego, libros que a su vez participan de la técnica narrativa de la novela urbana relatada en fragmentos con una amplísima galería de personajes que inauguró John Dos Passos con Manhattan Transfer -y que han proseguido destacados autores norteamericanos de la literatura posmoderna, como Thomas Pynchon, Don DeLillo y Paul Auster-. de anécdota, decir que el antónimo de los rackets serían los rednecks, es decir, los paletos del sur de Estados Unidos que pueblan las novelas de los dos autores señeros de la Gran Depresión: William Faulkner y John Steinbeck).

En su análisis de la estructura capitalista, Horkheimer-también Adorno, pero sobre todo Horkheimer-fue capaz de advertir que la democracia liberal, tal y como ya se apuntó con anterioridad en la cita de Daniel Bernabé, estaba deviniendo en el puro fascismo: «[Horkheimer] sostenía -escriben Hernández y Marzán- que el período económico capitalista de la libre competencia y la autorregulación del mercado habían llegado a su conclusión. Se transformaba en un régimen económico cada vez más controlado desde la esfera política ${ }^{21}$. No por casualidad durante las décadas de 1920 y 1930 se publicaron las primeras muestras de la narrativa distó-

Lo que mueve a los personajes de Eisner es el instinto de supervivencia en su estado más puro, la lucha por mantenerse en pie a cualquier precio y aunque sea a costa del otro -como dice uno de sus personajes, "todos luchamos en el agua, intentando asirnos a un tronco a flote para poder sobrevivir»-. Eisner muestra el lado más descarnado de la condición humana $\mathrm{y}$, sorprendentemente, lo hace sin incurrir en efectismos de saldo ni baratijas maniqueístas: sus libros se encuentran plagados de sordidez, injusticia, egoísmo, frustración, crueldad, avaricia, picaresca, maldad y, por supuesto, violencia, demostrado, así, que valores tan infantilizados por la cultura popular como «bien» $\mathrm{y}$ "mal» no pueden ajustarse de forma categórica a las personas en su empeño desesperado por salir del agujero y posicionarse en la escala social -como ha señalado el crítico Jordi Doce, evocando soterradamente al segundo Wittgenstein, «si algo escapa a las leyes de la lógica son las relaciones sociales, la vida social»-. Tanto en Ansia de vivir como en La avenida Dropsie se desentrańa la cara menos amable de las diferentes capas que conforman el sistema norteamericano: la burocracia, los bancos, los políticos, los periodistas, los empresarios, los autónomos, las religiones, la familia, las pandillas, los sindicatos y las mafias, estableciéndose, por cierto, un terrible paralelismo entre los dos últimos sectores, precisamente porque, como señala Horkheimer, «la sociedad bajo el capitalismo de Estado acaba configurándose como un conglomerado de grupos, capas, gremios, comités - distintos tipos de rackets - cuya función social no está determinada directamente por el beneficio, sino por la obtención y aumento de poder", p. 26.). 
pica, como El proceso, de Franz Kafka; Nosotros, de Yevgueni Zamiatin, o Un mundo feliz, de Aldous Huxley. En estas obras de ficción, igual que en las estructuras del capitalismo liberal, el individuo aparece diluido en medio de una sociedad tecnocrática que cada vez entiende menos y funciona a una velocidad cada vez mayor, una sociedad insaciable que le despoja de libertades y de autonomía y lo convierte en rehén de una superestructura burocrática. «El resultado de ese devenir -concluyen Hernández y Marcoses "una sociedad de desesperados", que cristaliza en sujetos que asumían pasivamente el poder, complacientes y sumisos respectos a las estructuras en las que se hallaban insertos $»^{22}$. Por esta razón, porque se trata de un modelo de control perfecto que sigue vigente, la ciudadanía se mantiene "como anestesiada por los disvalores del conformismo y la insensatez».

El artículo de Rayco José Herrera Reyes sobre la antropología filosófica de Günther Anders profundiza en la alienación de los individuos dentro del mundo tecnificado que denunciaron Horkheimer y Adorno, con la diferencia de que Anders no se muestra, en principio, tan pesimista y negativo como los autores frankfurtianos; de hecho, Herrera Reyes indica que la filosofía de la tecnología de Anders «se caracteriza sobre todo por la defensa del ser humano. Sus reflexiones acerca de la técnica son siempre una lucha por la salvación práctica, real y efectiva de los seres humanos y del mundo en el que vivimos ${ }^{23}$. No obstante -matiza Herrera Reyes-, el pensamiento de Anders no anda exento de paradojas, lo que explica que el filósofo polaco también asevere que los sujetos se hallan cada vez más determinados por el desarrollo tecnológico: «según Anders, lo que nos conforma hoy en día [...] son [...] los medios mismos, es decir, los dispositivos. Unos dispositivos que no son neutros. Por medio de su estructura y funciones fijas determinan de antemano el uso que haremos de ellos y así, también, nuestras ocupaciones y nuestros modos de vida ${ }^{24}$. Por supuesto, ese mundo técnico es "profundamente político" (y

22 Ibidem.

23 P. 100.

24 P. 105.
Herrera Reyes ilustra esa política de lo técnico con una serie de palabras significativas a la par que terribles: animal simbólico, falta de imaginación, mundo artificial o pasividad). Sin embargo", concluye Herrera Reyes, «mi percepción es que para Anders el ser humano encaja -demasiadoen el mundo técnico: es el engranaje perfecto $»^{25}$.

Precisamente ese encaje al que se refiere Herrera Reyes, y que se halla muy vinculado con las formas de control denunciadas por los miembros de la Escuela de Frankfurt, es la causa -volvemos a repetirlo- de que la ciudadanía se mantenga "como anestesiada por los disvalores del conformismo y la insensatez». En las actuales sociedades-pantalla-calificadas por algunos autores de totalitarismo virtual ${ }^{26}$-, los individuos se encuentran más controlados que nunca, pero no lo perciben, porque vivimos atrapados en la

25 P. 108.

26 Por ejemplo, José Luis Molinuevo en Humanismo y nuevas tecnologías, Madrid: Alianza, 2004, pp. 55-59. Uno de los puntos clave para entender dicho totalitarismo virtual pasa, en opinión de Molinuevo, por la ausencia de una cultura de las imágenes, puesto que nos hemos criado en "una cultura occidental de raíz platónica y judeocristiana, orientada a la palabra y no a la imagen, más aún, basada en el desprecio de la imagen" (p. 30). Nos encontramos, por tanto, con la paradoja perfecta: no hemos recibido una educación en la imagen, pero, sin embargo, «comemos millones de ellas» $\mathrm{y}$ "por medio de ellas el yo se transforma constantemente en otro" (p. 127). Recientemente Remedios Zafra ha dado buena nota de los peligros del exceso de información: «No es lo mismo unir que integrar [...]. La información, si es excesiva, atrofia y dificulta el conocimiento. Para conocer hay que saber prescindir. Solo en lo que integra sombras y vacío puede generarse pensamiento. Raramente puede surgir de lo abigarrado que no respira ni de la mera acumulación repetitiva", cf., R. ZAFra, Frágiles. Cartas sobre la ansiedad y la esperanza en la nueva cultura, Barcelona: Anagrama, 2021, p. 119. De manera que, si atendemos a las perspectivas de Molinuevo y Zafra, los sujetos de ahora consumen con voracidad miles de imágenes pese a no haber sido adiestrados en ellas, son verdaderos yonquis de las imágenes, y esa desmesurada acumulación de imágenes en la cabeza para lo único que sirve es para mantener a los individuos controlados mediante el aturdimiento visual, un aturdimiento que nunca es percibido como tal puesto que todos creen realizarse como personas a través de las imágenes que, asimismo, creen dominar. Nos encontramos, por tanto, ante el engranaje perfecto, sin duda alguna. 
fantasía digital del mismo modo que don Quijote vivía la fantasía de los libros, o sea, en la incapacidad de realizarnos, "de adquirir realidad, de ser propiamente ${ }^{27}$. Éste es el motivo de que para Remedios Zafra resulte "cínico hablar de libertad de elección cuando en estas formas se hilan las más clara estrategias de control $»^{28}$.

Sin embargo, a pesar del mencionado paralelismo, lo cierto es que existe una diferencia esencial respecto a la figura decante del don Quijote que se mueve en un mundo chabacano, y es que se trata de una ficción esculpida a través de la sobresaliente ironía cervantina ${ }^{29}$. Tal y como

27 P. 37. Como explica Francisco Javier Clemente Martín, «la alucinación quijotesca supone, en términos de la persecución de un ideal de existencia, la imposibilidad de ser aquel que se aspira a ser, la desrealización. Es la expresión de un idealismo desbocado, que se encuentra, a su vez, inscrito en el perfil de un entorno que no se presta a la fructificación de la alternativa, definido por la rigidez y el inmovilismo, descarnadamente superficial", p. 38.

28 R. Zafra, Frágiles, cit., p. 130. Tiago Santos, experto en formación de perfiles digitales, ha dado cuenta de los mecanismos de control de lo que somos rehenes con el teléfono móvil: «Por un lado somos muy cautos, les decimos por ejemplo a nuestros hijos que no hablen con desconocidos, pero a la vez les damos un móvil en el que van aceptando condiciones para poder avanzar»; "[en el móvil] no solo damos permiso para que accedan a nuestra información personal sino también a datos de otras personas que tenemos en nuestro móvil», ya que "en nuestro calendario del móvil tenemos las citas de trabajo, otras personas, teléfono, dirección, contactos de amigos. Al aceptar términos y condiciones de cualquier aplicación damos acceso al dispositivo, a la cámara, al micrófono, a la memoria del teléfono"; finalmente, respecto al micrófono en el móvil, dice Santos que «pueden escuchar nuestras conversaciones incluso cuando esa aplicación está apagada. Es cada vez más común y alarmante cómo tras tener una conversación con familiares o amigos te aparece en el móvil publicidad relacionada con los temas tratados», cf., La Vanguardia, 17/06/2021, entrevista que figura en última página del periódico, dentro de la sección "La Contra».

29 Dicha ironía es interpretada por F.J. Clemente Martín como un «movimiento conciliador», pues «la ironía dignifica y templa la imaginación, suaviza las asperezas que confrontan a este irreconciliablemente con lo establecido. Un pensamiento irónico a la manera cervantina evita los fantasmas del utopismo tanto como rechaza claudicar ante la tiranía de lo consuetudinario", pp. 37 y 39. ya se apuntó más atrás, Cervantes es uno de los pilares de la modernidad; otro de esos pilares es, qué duda cabe, Spinoza, cuya ética de la inmanencia tuvo la audacia de romper con el larguísimo dualismo alma/cuerpo al establecer que «la mente y el cuerpo son uno y el mismo individuo, que se concibe ora bajo el atributo del pensamiento, ora bajo el atributo de la extensión $»^{30}$. Y es que, como sostiene Vicente Hernández Pedrero, «hasta la redacción de la Ética demostrada según el orden geométrico, ninguna otra filosofía había planteado de manera tan radical y sistemática el vínculo material e inmanente entre la experiencia de transformación de los afectos del cuerpo y la generación de nuevas ideas emancipadoras en la mente»" ${ }^{31}$.

De manera que el proyecto de la modernidad en el que el liberalismo político despliega sus alas se inicia con la ironía cervantina y la inmanencia spinozista, y se cierra, en cierto modo, con la crítica nietzscheana de los valores absolutos. Sin lugar a dudas, Spinoza es la figura clave de esta atractiva evolución del pensamiento, a la vista de su valiente apuesta por una filosofía «no antropocéntrica» y radicalmente humanista, con la que debería producirse el racional salto evolutivo desde «un primer género "imaginario y no

30 Spinoza, Ética, II, 21, escolio. Cita rescatada de la tercera nota a pie de página del artículo de Hernández Pedrero, p. 46.

31 Ibidem. Para mayor profundización en la línea de investigación en la que ha venido trabajando el profesor Hernández Pedrero recomendamos su libro Etica de la inmanencia. El factor Spinoza, La Laguna, Servicio de Publicaciones de la Universidad de La Laguna, 2012. Dentro del presente volumen de Ética y política, el eficaz ensayo de Julio Alejandro Carreño Guillén ahonda en el decisivo papel que los afectos desempeñan dentro de la teoría de Spinoza (o, por decirlo a su modo, en el «encuentro entre cuerpos»), mientras que en el instructivo artículo de Jezabel Rodríguez Pérez se expone la proyección pedagógica de la ontología spinozista, «en la medida en que nos ofrece una definición bien concreta del ser humano", p. 79. Por último, en el texto de Sara Reyes Acosta se exploran las posibilidades de la danza como una filosofía de la corporeidad que la autora sitúa dentro del tercer género de conocimiento spinozista, «en tanto que está en conexión con las ideas de sabiduría (capacidad para conocer ciertas/muchas cosas) y de sensibilidad (capacidad para sentir ciertas/muchas cosas)», p. 94. 
adecuado" de conocimiento" ${ }^{32}$ hacia el excelso $-\mathrm{y}$ "tan difícil como raro»- tercer género de conocimiento. La propuesta filosófica de Spinoza es, de hecho, tan revolucionaria que actuales movimientos de liberación de la mujer se inspiran en la inmanencia spinozista; tal es el caso de la italiana Rosi Braidotti, la principal exponente de los postuhumanismos críticos. Su enfoque del concepto de vulnerabilidad es puesto en diálogo con el de otra importante filósofa feminista, la postestructuralista y teórica queer Judith Butler, en el segundo de los ensayos escrito a cuatro manos de este indisciplinado volumen: el que firman Myriam Hernández Domínguez y Mónica Cano Abadía. Para estas autoras, «los rasgos que definen el posthumanismo braidottiano descansan sobre una filosofía neo-materialista de la inmanencia que entiende que la materia es una y autopoiética, y que el sujeto no es unitario sino nomádico y en constante relación con una multitud de agente no-humanos ${ }^{33}$. Partiendo de esa base, prosiguen, la propuesta de la teoría poshumanista de Braidotti debe tener lugar con la necesaria aplicación de un "plano de encuentro" para los distintos sujetos que comparten afectos y tratan de mantener una creación colectiva ${ }^{34}$. Un plano de encuentro que «se opone tanto al conservadurismo liberal contemporáneo como al relativismo y al derrotismo nihilista " ${ }^{35}$, de ahí que la dimensión ética que propone Braidotti sea "afirmativa y de la alegría», lo que, en su opinión, "pasa por trascender la fuerza de lo negativo "reconociendo las emociones negativas como el dolor, la ira, la codicia y el miedo" ${ }^{36}$. Por esta razón Hernández Domínguez y Cano Abadía deciden centrarse en el concepto de la vulnerabilidad ya que, a pesar de la mala fama social que arrastra, se trata, como afirma Judith Butler, de "un rasgo constitutivo del sujeto", en la medida en que «existimos en una situación de vulnerabilidad frente a la pérdida, pérdida de reconocimiento, de la vida de otros o de nuestra propia vida», por lo que «no es posible estar al margen de esta condición de vulnerabilidad

\footnotetext{
32 P. 47.

33 P. 141.

34 P. 142.

35 P. 143

36 Pp. 144-145.
}

primaria $»^{37}$. A juicio de Braidotti, hay que asumir esa vulnerabilidad intrínseca de las personas y, por ende, común, para, de ese modo-ojalá-, vencer al terrible «individualismo egocéntrico» que nos tiene atado de pies y manos y poder, así, acercarnos, en la medida de la posible, «a la comprensión del "nosotros" ${ }^{38}$.

37 P. 146.

${ }^{38}$ Pp. 142 y 143 . El actual mundo-pantalla (que ya fue pronosticado en 2011 en los primeros episodios de la inquietante serie Black Mirror) ha consolidado el nefasto «individualismo egocéntrico» hasta extremos inimaginables. En 2009, el sociólogo norteamericano Jeremy Rifkin veía con buenos ojos la evolución que hasta entonces había tenido internet; a día de hoy su optimista análisis no ha podido quedar más desfasado. Según predijo Rifkin, internet iba a favorecer una sociedad más participativa que, por extensión, también sería empática y ello acabaría generando un capitalismo distributivo socialmente más sensible: «Internet - decía- está convirtiendo el mundo en una gigantesca ágora pública»; "La red, más que los encuentros sociales cara a cara, parece sacar a la luz el "verdadero yo" de la persona"; "Internet es una herramienta que permite compartir y colaborar", $c f$., J. Rifkin, La civilización empática. La carrera hacia una conciencia global en un mundo en crisis, Madrid: Paidós, 2010, pp. 534, 567 y 571. Pero no hagamos sangre; a posteriori se entiende la ingenua visión que Rifkin tuvo sobre internet y el mundo digital hace más de una década: en aquella época el portal YouTube todavía no había desarrollado la megaestructura con la que cuenta en estos momentos, ni existía el fenómeno de los youtubers y los influencers; Twitter era minoritario y WhatsApp, Instagram, Twitch y TikTok estaban por llegar. Por otro lado, cuando Rifkin realizó su diagnóstico no había el suficiente número de jóvenes criados en la nueva cultura tecnológica todavía en construcción. Ahora sí los hay, y el resultado no ha podido ser más catastrófico. Pero, para ser justos, en este último punto Rifkin sí encaminó mejor su olfato sociológico, pues supo alertar que internet estaba siendo el «despliegue de un exhibicionismo y un narcisismo ilimitados", cf., J. Rifkin, cit., p. 571. Rifkin no duda en seńalar que cada generación es sustancialmente más narcisista que la anterior: «A los jóvenes se les ha repetido hasta la náusea que son especiales, que todo lo que hacen tiene valor y es merecedor de elogio, que antes de nada deben quererse a sí mismos y que si lo hacen, el mundo reconocerá su singular talento y sus contribuciones y los alabará»; «El problema es que cuando son tanto los jóvenes que se sienten especiales y más importantes que los demás, se vuelven menos tolerantes, están menos dispuestos a aceptar una crítica sincera, son menos capaces de gestionar los fracasos-que son parte inevitable de la vida-y de expresar empatía con los demás», 
El ensayo de Miguel Mandujano Estrada que cierra el libro prosigue, de algún modo, con la vía emancipatoria impulsada por Rosi Braido-

cf., J. Rifkin, cit., pp. 573 y 575 . Y deja una incómoda pregunta en el aire: "¿Son los jóvenes realmente tan egocéntricos? ¿Hemos educado a una generación de narcisistas puros (monstruos, si se quiere) preocupados únicamente de sí mismos?», $c f$. . J. Rifkin, cit, p. 575. La respuesta, por desgracia, es inequívoca: sí, ya que la actual sociedad-pantalla no puede ser más narcisista e insensible (como afirmó Mario Bunge, la insensibilidad es «el efecto moral del individualismo radical», cf., M. Bunge, cit., p. 106); el problema es que el narcisismo es el primer rasgo de los psicópatas, y esa psicopatía puede radicalizarse aún más en este horizonte de pesadumbre. Nos encontramos, por tanto, en un escenario alejadísimo de la sociedad empática anhelada por Rifkin y de ese «nosotros» que reclama Rosi Braidotti. Porque lo tecnológico es el reino del Yo; el nosotros descabezado del pasado se ha convertido en una suma de despiadados yoes desesperados por llamar la atención, por obtener, como sea, el reconocimiento público. Especialmente trágico es el caso de los jóvenes, que se refugian en el móvil y aceptan una sobrexposición impúdica en las redes sociales en busca de la validación que no encuentran en los estudios, los deportes, las amistades o en el amor, lo que explica el reconocimiento que ha alcanzado en los últimos ańos la figura del youtuber, percibido por los jóvenes como el nuevo héroe, el "elegido", la marca visible y bien posicionada en la que ellos desean convertirse. Porque en la sociedad-pantalla no hay personas, sino marcas. Marcas hambrientas de público, deseosas de disponer de una red de seguidores/consumidores que justifique su existencia. Así, el consumo digital, cada vez más personalizado, contribuye a alejarnos del nosotros y reduce la conciencia de grupo; cada cual solo tiene en cuenta sus intereses, mientras que los intereses comunes han pasado a ser "otros intereses». Por eso no hay ni rastro de ironía o de crítica en la sociedad-pantalla, porque «o estás con mis intereses o estás contra mis intereses». Por eso estamos cada vez más fragmentados por sexo, edad, orientación ideológica, religión, actitud vital, etnia, preferencias alimenticias, preferencias de ocio, preferencias sexuales, nivel de estudios y niveles de ingresos. Dado que la heterogeneidad o sociodiversidad es amplísima y difícil de armonizar, el sentido de la pertenencia es cada vez más complejo. Cada sujeto se percibe exclusivo y alejado del conjunto adocenado. El conjunto, el nosotros, es asumido como una rémora del pasado. Porque lo único que importa es el Yo. La marca. Entretanto, los márgenes de libertad en los que podemos mostrarnos más vulnerables sin temor a las represalias o a sentirnos rechazados y, por tanto, sentirnos más nosotros mismos, son cada vez menores y más estrechos. tti, ya que se centra en el feminismo del tercer mundo en Estados Unidos que analiza la chicana Chela Sandoval, y que inspira, a su vez, el discurso del amor revolucionario de la activista franco-argelina Houria Bouteldja. El pensamiento de Sandoval -que bebe, entre otros, del de Roland Barthes y Franz Fanon- persigue, a través de ese feminismo del tercer mundo norteamericano, un igualitarismo "de resistencia» que case con las identidades, las otredades, las diferencias y las especificidades de las mujeres oprimidas $^{39}$. En opinión de Mandujano Estrada, la activista Bouteldja considera esa lucha de los oprimidos un acto de amor «con un principio autocrítico» $\mathrm{y}$ "político» ${ }^{40}$ que debe desembocar, en última instancia, en una "hermenéutica que guíe las "movidas" revolucionarias de la descolonización» ${ }^{41}$ y articule «la transformación social mediante otras formas de emancipación ${ }^{42}$.

Benito Romero

DOI: https://doi.org/10.25145/j.laguna.2021.48.06

\footnotetext{
39 P. 153.

40 P. 162.

41 Ibidem.

42 P. 163.
} 